\title{
Increased neuronal nitric oxide synthase dimerisation is involved in rat and human pancreatic beta cell hyperactivity in obesity
}

\author{
K. Mezghenna • P. Pomiès • A. Chalançon • F. Castex • J. Leroy • N. Niclauss • \\ B. Nadal • L. Cambier • C. Cazevieille • P. Petit • R. Gomis • T. Berney • R. Gross • \\ A. D. Lajoix
}

Received: 8 April 2011 / Accepted: 22 June 2011 / Published online: 18 August 2011

(C) Springer-Verlag 2011

\begin{abstract}
Aims/hypothesis Pancreatic beta cell hyperactivity is known to occur in obesity, particularly in insulin-resistant states. Our aim was to investigate whether changes in neuronal nitric oxide synthase (nNOS) function affect beta cell compensation in two relevant models: the Zucker fa/fa rats and pancreatic islets from obese humans.

Methods Glucose-induced insulin response was evaluated in the isolated perfused rat pancreas and in human pancreatic islets from obese individuals. Expression of $n N O S$ (also known as NOS1) and subcellular localisation of nNOS were studied by quantitative RT-PCR, immunoblotting, immunofluorescence and electron microscopy.

Results Pancreatic beta cells from Zucker $\mathrm{fa} / \mathrm{fa}$ rats and obese individuals were found to be hyper-responsive to glucose. Pharmacological blockade of nNOS was unable to modify beta cell response to glucose in $f a / f a$ rats and in
\end{abstract}

K. Mezghenna $\cdot$ A. Chalançon $\cdot$ F. Castex $\cdot$ J. Leroy $\cdot$ P. Petit $\cdot$

R. Gross $\cdot$ A. D. Lajoix $(\bowtie)$

University Montpellier 1, CNRS FRE 3400,

Centre for Pharmacology and Innovation in Diabetes (CPID),

Faculté de Pharmacie,

15 avenue Charles Flahault, BP 14491,

34093 Montpellier Cedex 5, France

e-mail: anne-dominique.lajoix@univ-montp1.fr

P. Pomiès $\cdot$ L. Cambier

CNRS UMR 5237, University Montpellier 1,

University Montpellier 2, Research Center of Macromolecular

Biochemistry (CRBM),

Montpellier, France

N. Niclauss $\cdot$ T. Berney

Department of Surgery, Cell Isolation and Transplantation Center,

Geneva University Hospitals and University of Geneva,

Geneva, Switzerland islets from obese individuals, suggesting an abnormal control of insulin secretion by the enzyme. In both cases, nNOS activity in islet cell extracts remained unchanged, despite a drastic increase in nNOS protein and an enhancement in the dimer/monomer ratio, pointing to the presence of high amounts of catalytically inactive enzyme. This relative decrease in activity could be mainly related to increases in islet asymmetric dimethyl-arginine content, an endogenous inhibitor of nNOS activity. In addition, mitochondrial nNOS level was decreased, which contrasts with a strongly increased association with insulin granules.

Conclusions/interpretation Increased nNOS production and dimerisation, together with a relative decrease in catalytic activity and relocalisation, are involved in beta cell hyperactivity in insulin-resistant rats but also in human islets isolated from obese individuals.

\section{B. Nadal $\cdot$ R. Gomis}

Laboratory of Diabetes and Obesity, Endocrinology

and Nutrition Unit, Institut d'Investigacions Biomèdiques

August Pi i Sunyer (IDIBAPS),

Barcelona, Spain

\section{B. Nadal $\cdot$ R. Gomis}

Centro de Investigación Biomédica en Red de Diabetes y

Enfermedades Metabólicas Asociadas (CIBERDEM),

Spain

URL: www.ciberdem.org

C. Cazevieille

Centre Régional d'Imagerie Cellulaire,

Montpellier, France 
Keywords Beta cell · Insulin secretion · NO synthase · Obesity · Type 2 diabetes

$\begin{array}{ll}\text { Abbreviations } \\ \text { ADMA } & \text { Asymmetric dimethyl-arginine } \\ \text { D-NAME } & N^{\omega} \text {-nitro-D-arginine methyl ester } \\ \text { L-MMA } & N^{\omega} \text {-methyl-L-arginine } \\ \text { L-NAME } & N^{\omega} \text {-nitro-L-arginine methyl ester } \\ \text { nNOS } & \text { Neuronal nitric oxide synthase } \\ \text { NO } & \text { Nitric oxide } \\ \text { PIN } & \text { Protein inhibitor of neuronal NOS } \\ \text { VDAC } & \text { Voltage-dependent anion channel }\end{array}$

\section{Introduction}

Type 2 diabetes is a heterogeneous disease due to a combination of genetic and environmental factors that contribute to insulin sensitivity and pancreatic beta cell function. Obesity and associated insulin resistance are major risk factors for the development of type 2 diabetes. During the long-lasting silent phase that occurs before the appearance of the clinical signs of diabetes, pancreatic beta cells compensate for insulin resistance by increased insulin secretion.

The physiological mechanisms underlying pancreatic beta cell compensation have been widely studied using the Zucker falfa rat [1], a relevant model that displays hyperphagia, obesity, insulin resistance and hyperinsulinaemia, resulting from a mutation in the leptin receptor [2]. The falfa rats compensate for insulin resistance partially through an increase in beta cell mass [3]. In addition, a primary defect in the beta cells also occurs, as neither in vivo starvation nor in vitro culture at low glucose concentration is able to decrease glucose-stimulated insulin secretion [4]. Furthermore, an innate hyperactivity of pancreatic beta cell response to feeding has been proposed to occur at least in some obese humans [5].

Early studies have shown that islets from $f a / f a$ rats exhibit an increased sensitivity to glucose [6]. An increase in glucose utilisation and oxidation, resulting from increased metabolic fluxes through pyruvate carboxylase and the malate-pyruvate and citrate-pyruvate shuttles, has been shown in islets from $f a / f a$ rats [7]. More recently, insulin hypersecretion in these animals has been proposed to result from an enhanced glucose-responsive fatty acid esterification/lipolysis process in beta cells [8]. In contrast, there have not been any studies in humans, until now, concerning the mechanism involved in beta cell hyperactivity.

To further investigate the mechanisms involved in beta cell hyperactivity in Zucker $f a / f a$ rats and obese individuals, we explored the function of neuronal nitric oxide (NO) synthase (nNOS), an enzyme responsible for the production of NO [9]. We have recently demonstrated that a neuronal isoform of NOS, produced in rat pancreatic beta cells, is able to control insulin secretion via both inhibitory and stimulatory effects [10]. Interestingly, we found nNOS mainly associated with the insulin secretory granules, but also with mitochondria and nuclei in beta cells. We also showed that the monomer/dimer equilibrium of the enzyme is able to influence the kinetics of glucose-induced insulin secretion and NO sensitivity [11].

Changes in nNOS activity/function could be involved in the pathogenesis of type 2 diabetes, as abnormally increased NO production has been shown to be involved in beta cell dysfunction in Goto-Kakizaki rats [12]. Using the Zucker falfa rat model and human pancreatic islets from obese individuals, we investigated whether nNOS changes could, at least partly, account for pancreatic beta cell hyperresponsiveness in obesity and/or insulin-resistant states.

\section{Methods}

Animals Male Zucker falfa rats and their control littermates, $\mathrm{fa} /+$ rats, were purchased from Harlan (Indianapolis, IN, USA). Tail blood samplings were taken before they were killed at 7 to 9 weeks of age. All experiments were conducted in accordance with the Principles of Laboratory Care.

Human characteristics Human islets were isolated at the University of Geneva Cell Isolation and Transplantation Centre from human pancreases harvested from brain-dead, heart-beating, multi-organ donors. The islets originated from two populations: lean individuals (BMI $<25 \mathrm{~kg} / \mathrm{m}^{2}$ ) and obese donors (BMI $>30 \mathrm{~kg} / \mathrm{m}^{2}$ ). We obtained islets from three lean individuals (two men, one woman, mean age $59 \pm 5.6$ years, mean BMI $24 \pm 0.55 \mathrm{~kg} / \mathrm{m}^{2}$ ) and from two obese women (mean age $54.5 \pm 8.5$ years; mean BMI $30.7 \pm 0.3 \mathrm{~kg} / \mathrm{m}^{2}$ ).

Isolation of rat and human islets Rat islets were isolated using digestion with collagenase P (Roche, Basel, Switzerland). Islets were handpicked under a stereomicroscope after separation with a Ficoll density gradient.

Human islets were isolated in Geneva as previously described by Bucher et al. [13] following a protocol approved by the Institutional Ethical Committee of Geneva University Hospital. They were cultured at $37^{\circ} \mathrm{C}$ in CMRL medium containing $5.6 \mathrm{mmol} / \mathrm{l}$ glucose and $10 \%$ fetal calf serum for 3-4 days before being sent to Montpellier for the next stage of the experiment.

Quantitative RT-PCR Total RNA from human islets was extracted with RNA Now Reagent (Biogentex, League City, 
TX, USA). First-strand cDNA was obtained from $5 \mu \mathrm{g}$ total RNA using Superscript II RNAse $\mathrm{H}^{-}$Reverse Transcriptase (Invitrogen, Paisley, UK). Quantitative real-time RT-PCR was performed with FastStart DNA Master SYBR Green I mix and a LightCycler (Roche).

Western blotting Human and freshly isolated rat islets were

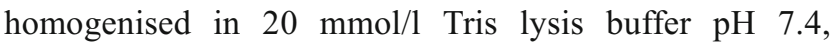
containing $150 \mathrm{mmol} / \mathrm{l} \mathrm{NaCl}, 1 \%$ Triton X-100 (vol./vol.), $0.1 \%$ SDS (vol./vol.) and a cocktail of protease inhibitors (Roche).

Proteins $(50 \mu \mathrm{g})$ were separated on a $7.5 \%$ SDSpolyacrylamide gel and transferred to a nitrocellulose membrane. Incubation with anti-nNOS (BD Biosciences, Franklin Lakes, NJ, USA), anti-phospho-Ser847-nNOS (Santa Cruz Biotechnology, Santa Cruz, CA, USA) or anti- $\alpha$-tubulin (as an internal control; Sigma, St Louis, MO, USA) antibodies was performed overnight and immunoreactivity was revealed by chemiluminescence. Signals were acquired and quantified by Bio 1D image analysis software (Vilber Lourmat, Marne-la-Vallée, France). Each experiment shown is representative of three independent western blots.

Low-temperature $6 \%$ SDS-PAGE at $10^{\circ} \mathrm{C}$ without boiling proteins $(50 \mu \mathrm{g})$ was used to study nNOS dimerisation [14]. In the case of INS- 1 cell extracts, the cells were first incubated in the presence of $5 \mathrm{mmol} / 1$ glucose $\pm 5 \mathrm{mmol} / 1 N^{\omega}$-nitro-Larginine methyl ester (L-NAME) and $10 \mu \mathrm{mol} / \mathrm{l}$ miconazole for $1 \mathrm{~h}$. After incubation, the cells were homogenised in lysis buffer as described above.

Immunofluorescence Cells isolated from pancreatic islets were obtained after dissociation with $0.025 \%$ trypsin/ $0.27 \mathrm{mmol} / 1$ EDTA (Sigma) and seeded on a poly-L-lysine (Sigma) coated Lab-Tek System. After 3 days of culture, they were immunostained overnight with anti-nNOS (EuroDiagnostica, Malmö, Sweden) and anti-insulin (Sigma) antibodies. Mitochondria were labelled with the mitochondrion-selective dye MitoTracker DeepRed 633 (Invitrogen). The negative control was performed by incubating the cells with only the secondary antibodies. Fluorescence was observed with the Bio-Rad MRC 1024 confocal microscope (Montpellier Rio Imaging, Montpellier, France). We used the ImageJ software (JACoP plugins) to calculate the Pearson coefficient with a Costes' automatic threshold.

Electron microscopy Freshly isolated islets were fixed using $2.5 \%$ paraformaldehyde (wt/vol.) and $0.1 \%$ glutaraldehyde (vol./vol.) and routinely embedded in LR White. Ultrathin sections of $60 \mathrm{~nm}$ were immunostained with antinNOS (Euro-Diagnostica) and anti-insulin (Sigma) antibodies and with secondary antibodies labelled with 15 or
$5 \mathrm{~nm}$ gold particles, respectively (British Biocell, Cardiff, UK). Sections were observed with a transmission electron microscope (Hitachi H-7100). The specificity of the immune reaction was tested by incubating the sections with only the secondary antibodies.

Subcellular fractionation Isolated rat islets pooled from three different animals were blended with a Dounce homogeniser. Nuclei and unbroken cells were removed by centrifugation at $1,000 \mathrm{~g}$ for $10 \mathrm{~min}$. Mitochondria were then isolated from the cytosolic fraction by further centrifugation for $15 \mathrm{~min}$ at $16,000 \mathrm{~g}$. The pellet of mitochondria was resuspended in a mixture of $10 \mathrm{mmol} / \mathrm{l}$ Tris- $\mathrm{HCl} \mathrm{pH} 7.5,250 \mathrm{mmol} / \mathrm{l}$ sucrose and $1 \mathrm{mmol} / 1$ EDTA- $0.1 \%$ ethanol (vol./vol.) and the suspension was subsequently centrifuged for $15 \mathrm{~min}$ at $16,000 \mathrm{~g}$ at $4^{\circ} \mathrm{C}$. The purity of cytosolic and mitochondrial fractions was assessed by, respectively, anti- $\alpha$-tubulin (Sigma) and anti-voltage-dependent anion channel (VDAC; Abcam, Cambridge, UK) antibodies.

Isolated islets incubation experiments Human isolated islets were stabilised in $\mathrm{KRB}$ with $2.8 \mathrm{mmol} / 1$ glucose for $2 \mathrm{~h}$ at $37^{\circ} \mathrm{C}$. Groups of ten islets were then incubated in KRB with $2.8,8.3$ or $16.7 \mathrm{mmol} / 1$ glucose for $90 \mathrm{~min}$ at $37^{\circ} \mathrm{C} \pm 10 \mathrm{mmol} / 1 \mathrm{~L}-\mathrm{NAME}, 10 \mathrm{mmol} / 1 \mathrm{~N}^{\mathrm{\omega}}$ nitro-D-arginine methyl ester (D-NAME) or $5 \mu \mathrm{mol} / 1$ miconazole. Each experimental condition was repeated ten times. Supernatant fractions were sampled and insulin release estimated by an HTRF Insulin assay (Cis Bio, Saclay, France).

Isolated perfused rat pancreas studies Lean $(\sim 200 \mathrm{~g})$ and obese ( $\sim 300 \mathrm{~g})$ age-matched Zucker rats were anaesthetised with sodium pentobarbitone $(60 \mathrm{mg} / \mathrm{kg}$ i.p.). Isolated pancreases were perfused according to procedures described by Lajoix et al. [10]. Insulin secretion values, obtained by RIA (Linco, St Charles, MO, USA), are plotted on the figures as means \pm SEM but also as mean integrated data obtained by calculating the AUC during 20 min of high glucose $(11 \mathrm{mmol} / \mathrm{l})$ administration.

nNOS catalytic activity assay nNOS catalytic activity was estimated in islet extracts by measuring the production of radiolabelled $\left[{ }^{3} \mathrm{H}\right]$ citrulline from $\left[{ }^{3} \mathrm{H}\right]$ arginine (MP Biomedicals, Irvine, CA, USA), according to the manufacturer's recommendations (Nitric Oxide Synthase Assay Kit; Merck Biosciences, Whitehouse Station, NJ, USA).

Asymmetric dimethyl-arginine immunoassay Asymmetric dimethyl-arginine (ADMA) concentrations were determined in proteic extracts from rat and human islets using the ADMA ELISA kit (Immundiagnostik, Bensheim, Germany) according to the manufacturer's recommendations. 


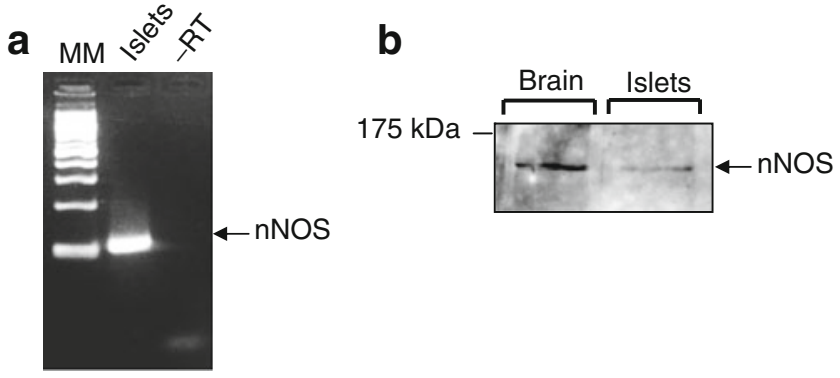

Fig. 1 Analysis of $n N O S$ expression in human islets. a Expression of $n N O S$ analysed by RT-PCR. b Western blotting analysis of nNOS in human islets and rat brain (used as a positive control). $-\mathrm{RT}$, negative control for PCR preparation; MM, molecular mass markers

Statistical analysis Experimental values represent the mean of $n$ experiments and are plotted on the graphs as means \pm SEM. The data were analysed using a Student's $t$ test.

\section{Results}

Expression of the neuronal isoform of NOS in human islets Using RT-PCR, we amplified a fragment that corresponds, after sequencing, to human $n N O S$ (also known as NOS1) (Fig. 1a). Western blotting confirmed the presence of the $160 \mathrm{kDa}$ nNOS protein, identical to rat brain nNOS (Fig. 1b).

Evidence for beta cell hyperactivity in Zucker fa/fa rat isolated pancreas and in human islets from obese humans In the isolated perfused pancreas of Zucker $\mathrm{fa} /+$ rats, raising glucose concentration from 4.2 to $11 \mathrm{mmol} / \mathrm{l}$ provoked a classic biphasic insulin response with a mean integrated response of $658.8 \pm 83.9 \mathrm{ng} \times 20 \mathrm{~min}(n=8)($ Fig. 2a, b)
When compared with $f a /+$ rats, $f a / f a$ rats were clearly hyper-responsive to glucose $(1,838.9 \pm 224.6 \mathrm{ng} \times 20 \mathrm{~min}$; $p<0.001$ vs $f a /+$ rats; $n=10$ ) (Fig. $2 \mathrm{a}, \mathrm{b}$ ). In human islets from lean individuals, basal insulin secretion was $10.1 \pm$ $0.8 \mathrm{ng}(90 \mathrm{~min})^{-1}(10 \text { islets })^{-1}$ and increased to $15.3 \pm$ $1.3 \mathrm{ng}(90 \mathrm{~min})^{-1}(10 \text { islets })^{-1}$ at $8.3 \mathrm{mmol} / 1$ glucose and $21.3 \pm 1.9 \mathrm{ng}(90 \mathrm{~min})^{-1}(10 \text { islets })^{-1}$ at $16.7 \mathrm{mmol} / 1$ glucose ( $p<0.001$ vs $2.8 \mathrm{mmol} / 1$ glucose; $n=3$ ) (Fig. 2c). In contrast, human islets from obese individuals appeared to be clearly hyper-responsive to glucose, even at the low $2.8 \mathrm{mmol} / 1$ concentration $\left(19.4 \pm 2 \mathrm{ng}[90 \mathrm{~min}]^{-1}\right.$ $[10 \text { islets }]^{-1} ; p<0.001$ vs lean individuals; $\left.n=2\right)$. At $8.3 \mathrm{mmol} / 1$ glucose, insulin secretion reached $31.2 \pm$ $2.8 \mathrm{ng}(90 \mathrm{~min})^{-1} \quad(10 \text { islets })^{-1} \quad(p<0.001$ vs lean individuals) and did not further increase in the presence of $16.7 \mathrm{mmol} / 1$ glucose $\left(31.2 \pm 3.2 \mathrm{ng}[90 \mathrm{~min}]^{-1}[10\right.$

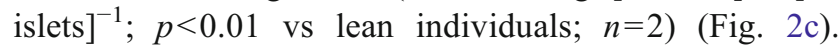
Importantly, we observed no difference in islet size between the lean and obese groups.

Effects of nNOS blockade with L-NAME on glucoseinduced insulin secretion In $\mathrm{fa} /+$ rats, L-NAME $(5 \mathrm{mmol} / \mathrm{l})$ potentiated, as in Wistar rats [10], insulin release to $1,027 \pm$ $133.2 \mathrm{ng} \times 20 \mathrm{~min}(p<0.05 ; n=8)$ (Fig. 3a, b). However, in $f a / f a$ rats, L-NAME was no longer able to significantly modify glucose-induced insulin secretion $(1,728.2 \pm$ $220.3 \mathrm{ng} \times 20 \mathrm{~min} ; n=7$ ) (Fig. 3c, d). In human islets from lean individuals, L-NAME $(10 \mathrm{mmol} / \mathrm{l})$ significantly stimulated insulin secretion from $15.3 \pm 1.3$ to $22.4 \pm 2.4 \mathrm{ng}$ $(90 \mathrm{~min})^{-1}(10 \text { islets })^{-1}$ at $8.3 \mathrm{mmol} / 1$ glucose $(p<0.01)$ and from $21.3 \pm 1.9$ to $27.7 \pm 2.8 \mathrm{ng}(90 \mathrm{~min})^{-1}(10 \text { islets })^{-1}$ at $16.7 \mathrm{mmol} / 1$ glucose $(p<0.05 ; n=3)$ (Fig. 3e). In contrast, insulin secretion was not modified by L-NAME in human islets from obese individuals at any of the two glucose concentrations $(n=2)$ (Fig. 3e). In both cases, the L-NAME

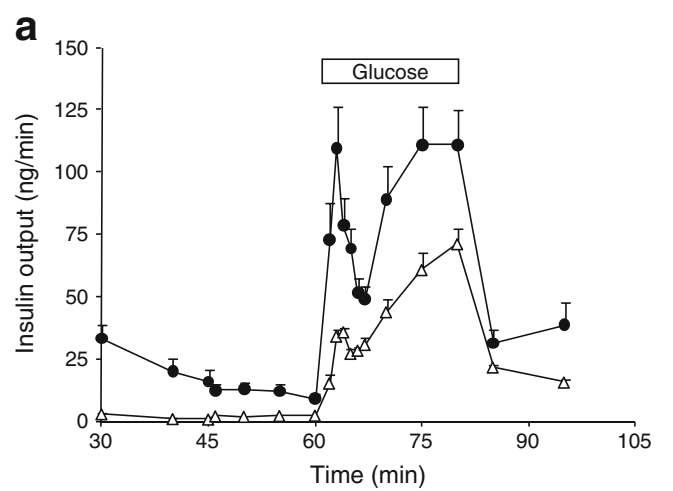

Fig. 2 Insulin response to glucose in Zucker $f a /+$ and $f a / f a$ rats and in islets from lean and obese humans. a Effect of $11 \mathrm{mmol} / 1$ glucose in the isolated perfused rat pancreas from $f a /+(n=8)$ vs $f a / f a$ rats $(p<0.001 ; n=10)$. Basal glucose background: $4.2 \mathrm{mmol} / 1$. $f a /+$ rats, white triangles; $f a / f a$ rats, black circles; b Mean integrated insulin
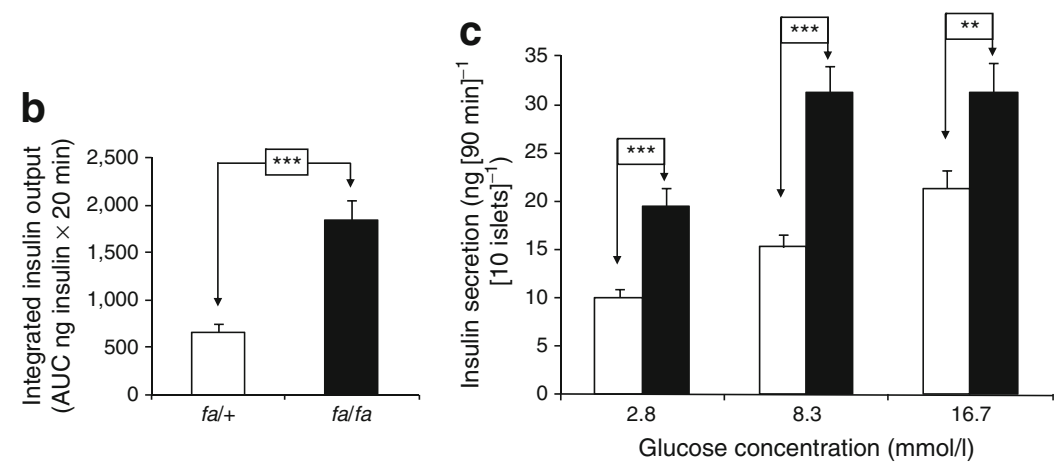

output in response to glucose in $f a /+$ and $f a / f a$ rats. c Insulin response to $2.8,8.3$ and $16.7 \mathrm{mmol} / 1$ glucose in isolated islets from lean $(n=3)$ and obese $(n=2)$ humans. ${ }^{* *} p<0.01,{ }^{* * *} p<0.001$. White bars, lean humans; black bars, obese humans 
Fig. 3 Effect of L-NAME on insulin response to glucose in Zucker $f a /+$ and $f a / f a$ rats and in islets from lean and obese humans. a Effect of $5 \mathrm{mmol} / \mathrm{l}$ L-NAME in the presence of $11 \mathrm{mmol} / 1$ glucose $(p<0.05$; $n=8$ for both groups) in the isolated perfused rat pancreas from $\mathrm{fa} /+$ rats. Basal glucose background: $4.2 \mathrm{mmol} / \mathrm{l}$. White circles, +5 mmol/l L-NAME; black triangles, glucose only. b Mean integrated insulin output in the presence of L-NAME in $\mathrm{fa} /+$ rats. c Effect of $5 \mathrm{mmol} / \mathrm{l}$ L-NAME in the presence of $11 \mathrm{mmol} / \mathrm{l}$ glucose $(n=7)$ in the isolated perfused rat pancreas from $f a / f a$ rats. White squares, $+5 \mathrm{mmol} / \mathrm{l} \mathrm{L}$-NAME; black circles, glucose only $(n=10)$. d Mean integrated insulin output in the presence of L-NAME in falfa rats. e Effect of $10 \mathrm{mmol} / \mathrm{l}$ L-NAME and D-NAME in the presence of 8.3 and $16.7 \mathrm{mmol} / \mathrm{l}$ glucose in isolated islets from lean individuals $(n=3)$ vs obese individuals $(n=2)$. ${ }^{*} p<0.05, * * p<0.01$. Grey bars, $+10 \mathrm{mmol} / \mathrm{l} \mathrm{L}-\mathrm{NAME}$; black bars, $+10 \mathrm{mmol} / \mathrm{l}$ D-NAME; white bars, glucose only
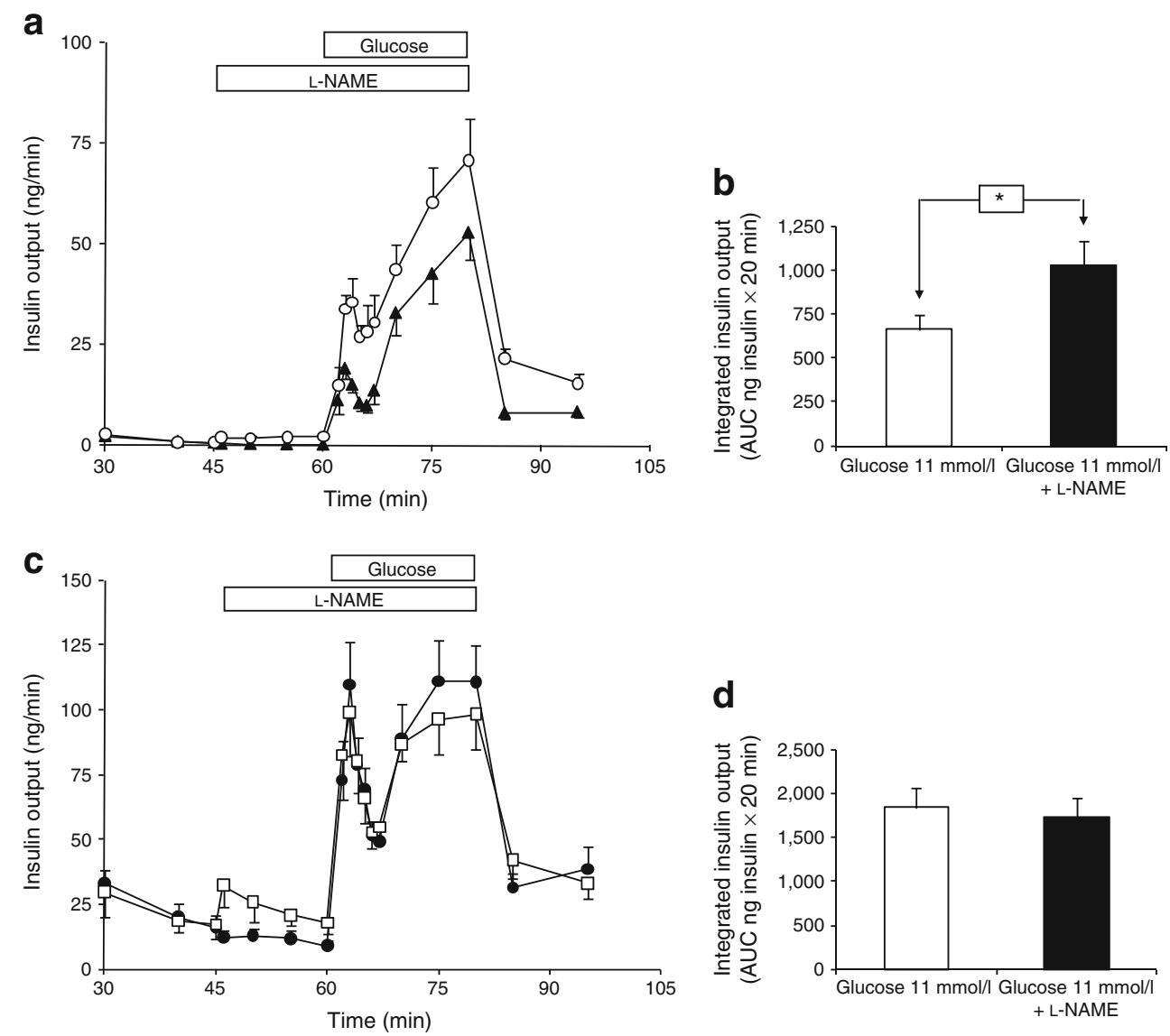

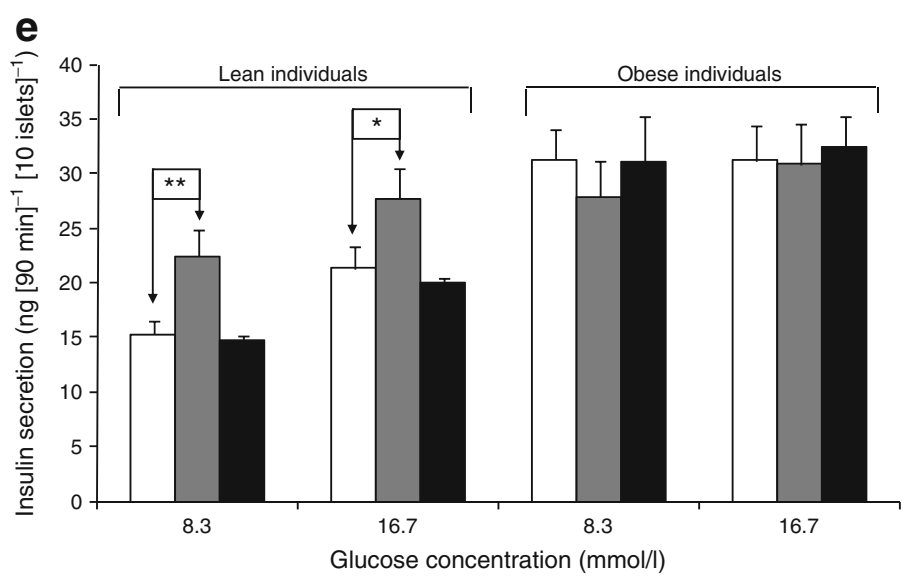

stimulatory effect was not related to a possible non-specific membrane depolarisation, as D-NAME (10 mmol/l) appeared ineffective.

Alterations of $n N O S$ catalytic activity The lack of an L-NAME effect on insulin secretion in both isolated rat pancreas and human islets could be related to alterations in nNOS catalytic activity. The latter was found unchanged in $f a / f a$ vs $f a /+$ islet extracts $(n=3)$ (Fig. 4a). Likewise, in human islets from obese individuals, nNOS activity remained unchanged compared with lean individuals $(n=2$ or 3) (Fig. 4b).
Increased nNOS expression in pancreatic islets Quantitative RT-PCR (Fig. 4c) and western blotting (Fig. 4e) analysis revealed respectively a 3.6- and a sevenfold overexpression of $n N o s$ in $f a / f a$ rats $(p<0.05 ; n=3)$, which contrasts with the unchanged nNOS activity in these animals. However, when nNOS activity is expressed relative to nNOS protein level, the ratio achieved was sixto sevenfold lower in $f a / f a$ vs $f a /+$ rats, pointing to a strong decrease in the enzyme catalytic activity. In human islets from obese individuals, $n N O S$ mRNA (Fig. 4d) and protein (Fig. 4f) was also found to be overexpressed by, respectively, $78 \%$ and threefold compared with lean individuals $(p<0.05$; 

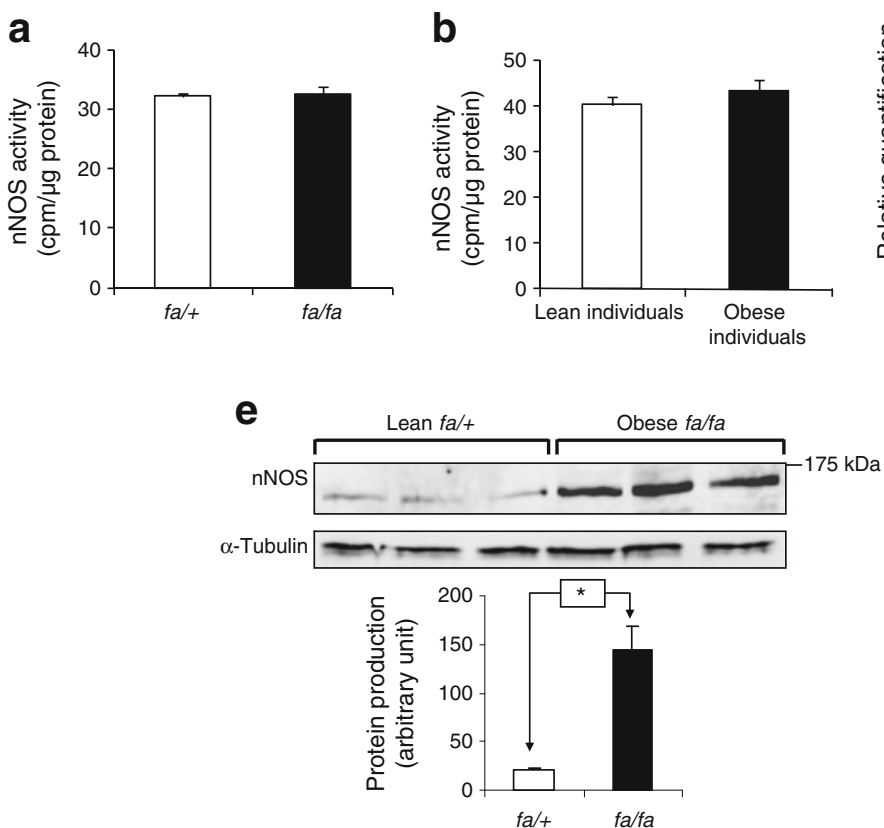

Fig. 4 Analysis of nNOS catalytic activity and expression in rat and human islets. nNOS catalytic activity in islet extracts from (a) $f a /+$ vs $f a / f a$ rats $(n=3)$ and (b) lean $(n=3)$ vs obese $(n=2)$ individuals. NO production was measured after conversion of radiolabelled arginine into radiolabelled citrulline on islet extracts, according to the manufacturer's recommendations. Expression of $n N o s$ by quantitative

$n=2$ or 3 ). nNOS activity expressed relative to nNOS protein content was also decreased by threefold in human islets from obese individuals.

Increased nNOS dimerisation and phosphorylation in pancreatic islets If only faint amounts of nNOS dimers could be detected in $f a /+$ rats, we found 7.6-fold more SDS-resistant nNOS dimers in $f a / f a$ rats $(p<0.001)$ (Fig. 5a). Moreover, the dimer/monomer ratio was 1.8 -fold higher in $f a / f a$ rats than in $f a /+$ rats. In human islets, we observed 2.3-fold more nNOS dimers in islets from obese individuals compared with lean controls $(p<0.05)$, with a 1.8-fold higher dimer/monomer ratio (Fig. 5b). This high amount of dimers contrasts with the relative decrease in nNOS catalytic activity we observed and suggests the presence of catalytically inactive dimers. We measured the amount of ADMA, an endogenous inhibitor of nNOS able to promote nNOS dimerisation [11], in islet cellular extracts. Intracellular ADMA concentration was increased by 5.75 -fold in islet extracts from $f a l f a$ vs $f a /+$ rats $(p<0.01, n=5)$ (Fig. $5 c$ ) and by 2.35 -fold in human islets from obese vs lean individuals $(p<0.05$; obese $n=2$, lean $n=3)$ (Fig. $5 \mathrm{~d}$ ). We also investigated the possible involvement of nNOS phosphorylation at serine 847 , which is known to inactivate the enzyme
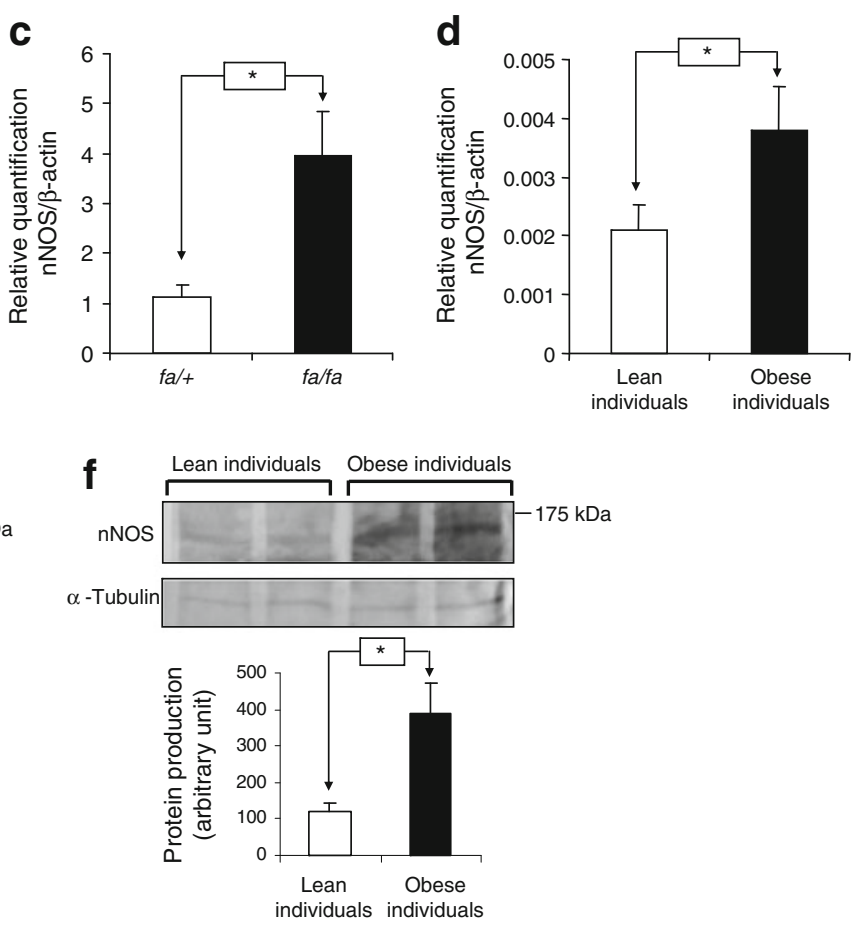

real-time RT-PCR in $f a /+$ vs $f a / f a$ rats (c) and in lean vs obese humans (d). Western blotting analysis of nNOS in $f a /+$ vs $f a / f a$ rats (e) and in lean vs obese individuals (f). Upper panel: nNOS immunoreactivity was revealed by a monoclonal anti-nNOS antibody (representative of three independent experiments). Lower panel: relative quantification of the band intensities by Bio 1D image analysis software. ${ }^{*} p<0.05$

by inhibiting $\mathrm{Ca}^{2+} /$ calmodulin binding [15]. Interestingly, we found phospho-dimers in islets from both $f a /+$ and $f a l f a$ rats with a 2.7 -fold increase in the latter, which probably plays only a minor role in the relative decrease in nNOS activity.

Effects of downregulation of nNOS dimerisation by miconazole on glucose-induced insulin secretion In order to downregulate nNOS dimerisation, we used the antifungal imidazole, miconazole, previously shown to block assembly of inducible NOS into active dimers through binding to the haem iron [16]. We first confirmed that miconazole $(10 \mu \mathrm{mol} / \mathrm{l})$ strongly decreased nNOS dimerisation and glucose-induced insulin secretion promoted by L-NAME in the INS-1 cell line (Fig. 6a). In the isolated perfused pancreas, miconazole $(5 \mu \mathrm{mol} / \mathrm{l})$, used at a concentration ineffective in control $\mathrm{fa} /+$ animals, reduced insulin response to $11 \mathrm{mmol} / 1$ glucose in $f a / f a$ rats by $41 \%(p<$ $0.01 ; n=6$ ) (Fig. 6b). In islets from obese individuals, miconazole was also able to reduce insulin response to 8.3 and $16.7 \mathrm{mmol} / \mathrm{l}$ glucose by, respectively, $28 \%(p<0.05)$ and $43 \%(p<0.001 ; n=2)$ (Fig. $6 c)$.

Alterations in nNOS localisation in pancreatic beta cells We performed immunofluorescence studies on isolat- 

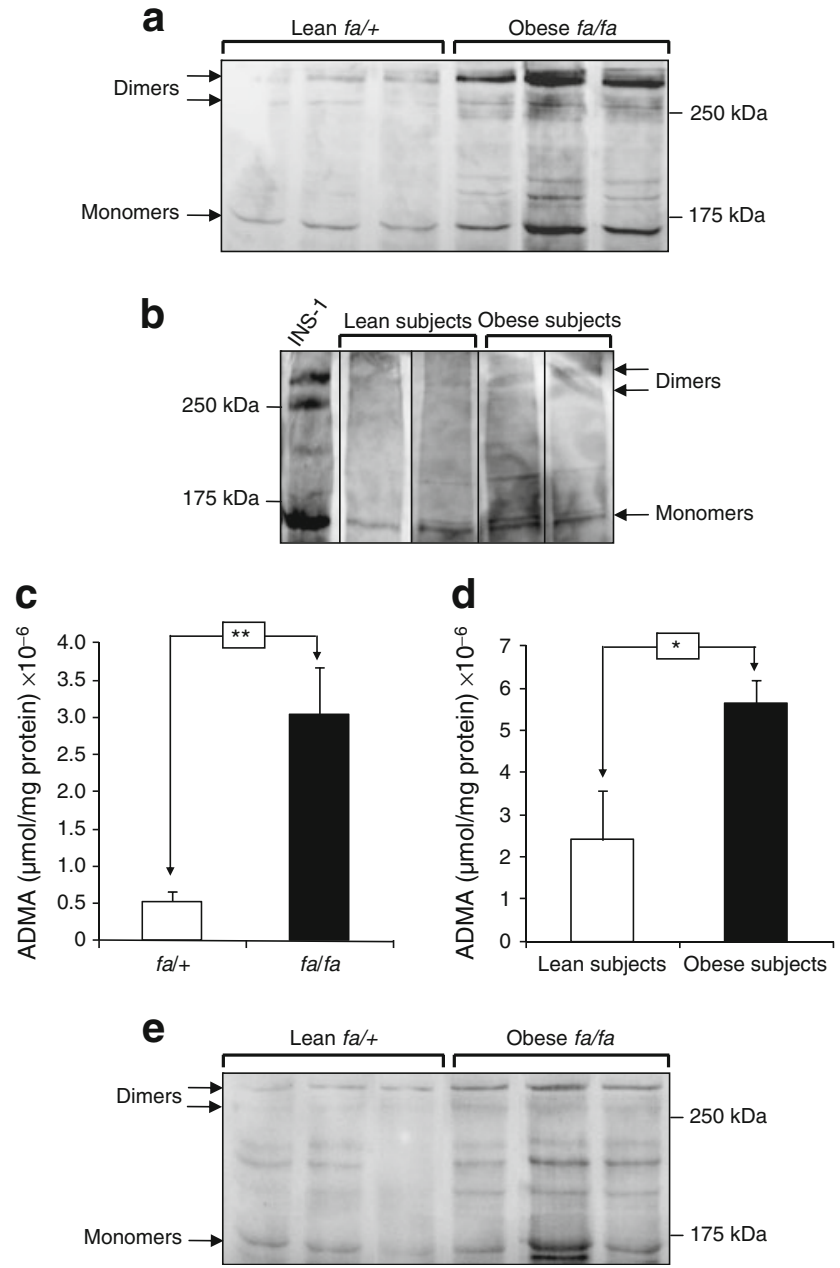

Fig. 5 Analysis of nNOS dimerisation and phosphorylation in rat and human islets. nNOS dimeric state in $f a / f a$ vs $f a /+$ rats (a) and in lean vs obese individuals (b). The dimer/monomer equilibrium was analysed by low-temperature SDS-PAGE and subsequent western blotting with the monoclonal anti-nNOS antibody (representative of three independent experiments). Monomers and dimers are indicated by arrows. INS-1 cells incubated with L-NAME were used as a positive control. ADMA concentrations in islets from $f a /+$ vs $f a / f a$ rats (c) and from lean vs obese individuals (d). ADMA was measured by a competitive ELISA according to the manufacturer's protocol. e nNOS phosphorylation at serine 847 in $f a / f a$ vs $f a /+$ rats (representative of three independent experiments). Low-temperature SDS-PAGE was performed, followed by western blotting with a rabbit anti-Ser847PnNOS antibody. Monomers and dimers are indicated by arrows. ${ }^{*} p<$ $0.05, * * p<0.01$

ed beta cells obtained from rat (Fig. 7a-1) and human (Fig. $7 \mathrm{~m}-\mathrm{r}$ ) islets, using anti-nNOS (red) and anti-insulin antibodies (green). In falfa rats (Fig. $7 \mathrm{~g}-1$ ), nNOS displayed a $28.3 \pm 0.6 \%$ greater association with insulin granules (according to the Pearson coefficient; $p<0.01 ; n=3$ ) (compare Fig. $7 \mathrm{k}$ and e) than in $f a /+$ rats (Fig. $7 \mathrm{a}-\mathrm{f}$ ). In human beta cells from obese individuals (Fig. 7p-r), we found a $15 \pm 1 \%$ greater nNOS colocalisation with insulin granules $(p<0.05 ; n=3)$ (compare Fig. $7 \mathrm{r}$ and o) compared with lean individuals (Fig. $7 \mathrm{~m}-\mathrm{o}$ ). In $f a /+$ rats, a great part of nNOS was also present in beta cell mitochondria (Fig. 7c), as shown by MitoTracker Deep Red 633 staining (blue, Fig. 7a, g). In contrast, nNOS was present in lower amounts in mitochondria from $f a / f a$ rats (Fig. 7i). It should also be noted that the distribution/density of mitochondria was changed, with a more intense and punctuated labelling than in $f a /+$ rats (compare Fig. $7 \mathrm{a}$ and g). Moreover, in $f a / f a$ animals and obese individuals, the nNOS level was greater in the nucleus (Fig. 7b, h). Changes in nNOS localisation were confirmed by subcellular fractionation of islets pooled from three different $f a /+$ and $f a / f a$ rats. Our immunoblots showed that nNOS amounts were increased in the cytosolic fraction, whereas the enzyme was present in lower amounts in the mitochondrial fraction of falfa islets (Fig. 8a). Our full data on the changes in nNOS expression and subcellular localisation are strongly supported by electron microscopy studies performed on human islet sections. First, we confirmed that nNOS is associated, in human beta cells, with the membrane and the dense core of insulin granules at different stages of maturation (Fig. 8d), as well as with mitochondria (Fig. 8c) and nucleus (data not shown), as previously observed in rats [10]. In addition, more nNOS was found associated with insulin granules (Fig. 8e, f) and less with mitochondria (Fig. 8c) in obese vs lean individuals (Fig 8b [insulin granules], d [mitochondria]).

\section{Discussion}

In our early studies [17], we showed that inhibition of nNOS by L-NAME, a potent competitive inhibitor of constitutive NOS activity, was able to convert the biphasic pattern of insulin response to glucose into a significantly greater monophasic one [10]. Interestingly, the L-NAME effect was associated with changes in the dimer/monomer ratio, with the appearance of a higher amount of stable nNOS dimers [11]. These observations prompted us to propose that changes in nNOS function and dimerisation could be involved in certain hyperinsulinaemic states associated with insulin resistance and obesity.

In Zucker $f a / f a$ rats, hyperinsulinaemia that compensates for insulin resistance clearly results from an increased sensitivity of the beta cell to glucose [4, 6-8]. In addition, beta cell hyperactivity in $f a / f a$ rats is associated with a $3.8 \%$ increased mass. Indeed, previous studies in obese rats have reported the presence of enlarged islets with an increase in beta cell mass, as well as beta cell hypertrophy $[6,18]$. Beta cell hypertrophy is accompanied by an increased amount of secretory cells at $5.5-11 \mathrm{mmol} / \mathrm{l}$ glucose, increased secretion per cell at low glucose concentrations, and decreased 

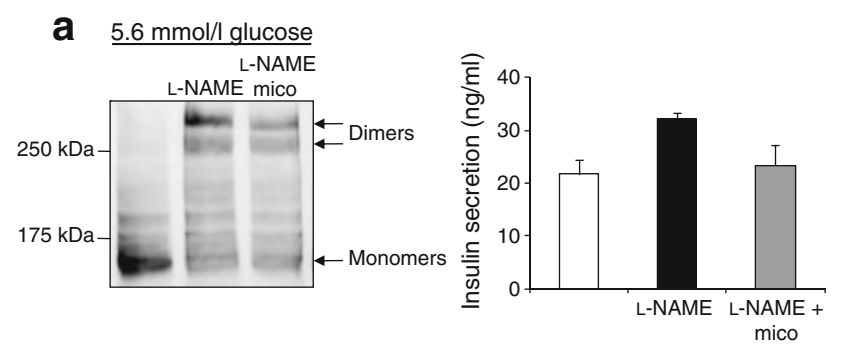

b

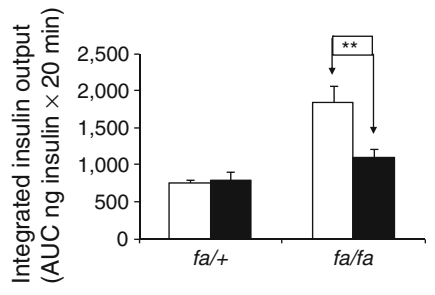

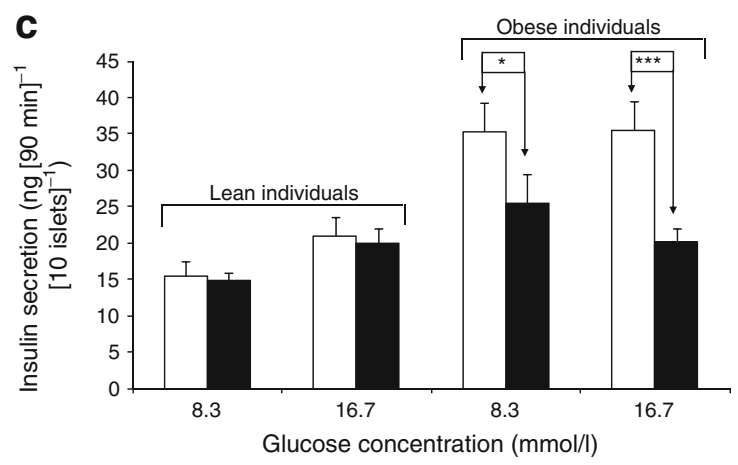

Fig. 6 Effect of miconazole on nNOS dimerisation and on insulin response to glucose. a Effect of miconazole $(10 \mu \mathrm{mol} / \mathrm{l})$ on nNOS dimerisation and insulin secretion promoted by $5 \mathrm{mmol} / \mathrm{l}$ L-NAME in INS-1 cells. The dimer/monomer equilibrium was analysed by lowtemperature SDS-PAGE and subsequent western blotting $(n=3)$. Insulin secretion is induced by $5.6 \mathrm{mmol} / \mathrm{l}$ glucose. $\mathbf{b}$ Mean integrated insulin output in the presence of $5 \mu \mathrm{mol} / 1$ miconazole in the isolated perfused rat pancreas of $f a /+$ and $f a / f a$ rats ( $n=6$ for both groups). Black bars, $+5 \mu \mathrm{mol} / 1$ miconazole; white bars, glucose only. $\mathbf{c}$ Effect of $10 \mu \mathrm{mol} / \mathrm{l}$ miconazole in the presence of 8.3 and $16.7 \mathrm{mmol} / \mathrm{l}$ glucose in isolated islets from lean $(n=3)$ vs obese $(n=2)$ individuals. Black bars, $+10 \mu \mathrm{mol} / 1$ miconazole; white bars, glucose only. ${ }^{*} p<$ $0.05,{ }^{* *} p<0.01, * * * p<0.001$. mico, miconazole

individuals provides pharmacological evidence for a defect in pancreatic beta cell nNOS functional activity. A decrease in nNOS oxidative catalytic activity has previously been reported in the stomach fundus and the hypothalamus of falfa rats [23], whereas no data are available concerning possible changes in nNOS in obese humans. In our study, we found no change in nNOS catalytic activity in islet protein extracts. However, owing to a drastic increase in nNOS protein level, the overall enzyme activity appeared drastically reduced. $n N O S$ overexpression could be due to an enhanced activity of transcription factors, as nuclear factor kappa-B (NFKB) and cAMP response element (CRE) are reportedly involved in nNOS induction [24-26]. In addition, the dimeric conformation of nNOS has been shown to protect the protein from proteolysis by the ubiquitinproteasome pathway [27]. However, despite a sevenfold increase in nNOS protein level, we found only a 2.7 -fold increase in phospho-Ser847 in $f a / f a$ rats, which plays probably only a minor role in the relative reduction of nNOS activity.

Of main interest is the strong increase in the amount of SDS-resistant nNOS dimers we found in $f a / f a$ rats and obese individuals. The ability of L-NAME to induce stable nNOS dimers is shared by $N^{\omega}$-methyl-L-arginine (Linsulin secretion in islets issued from $f a / f a$ rats and obese 

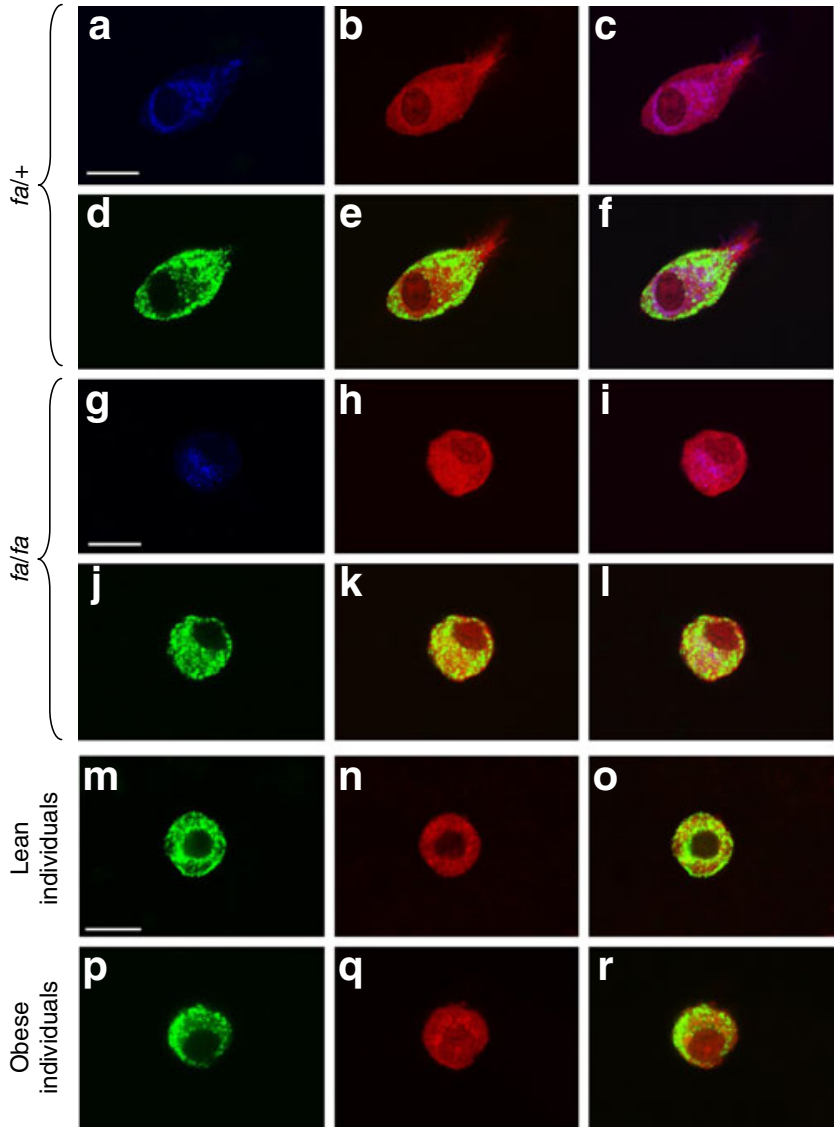

Fig. 7 Analysis of nNOS localisation in rat and human islets. a-l Localisation of nNOS in isolated beta cells from $\mathrm{fa} /+$ and $\mathrm{fa} / \mathrm{fa}$ rats by immunofluorescence. Isolated beta cells from $f a /+(\mathbf{a}-\mathbf{f})$ and $f a / f a(\mathbf{g}-\mathbf{l})$ rats were triple labelled with an anti-insulin ( $\mathbf{d}, \mathbf{j}$ green), an anti-nNOS antibody (b, h red) and MitoTracker Deep Red 633 (a, $\mathbf{g}$ blue). Coincidence of: nNOS and MitoTracker fluorescence is shown in $\mathbf{c}$ and $\mathbf{i}$; nNOS and insulin in $\mathbf{e}$ and $\mathbf{k}$; and finally nNOS, insulin and MitoTracker in $\mathbf{f}$ and $\mathbf{l} . \mathbf{m}-\mathbf{r}$ Localisation of nNOS in isolated beta cells from lean and obese individuals by immunofluorescence. Isolated beta cells from lean $(\mathbf{m}-\mathbf{0})$ and obese $(\mathbf{p}-\mathbf{r})$ individuals were double labelled with an anti-insulin ( $\mathbf{m}, \mathbf{p}$ green) and an anti-nNOS antibody ( $\mathbf{n}, \mathbf{q}$ red). Coincidence of nNOS and insulin fluorescence is shown in $\mathbf{o}$ and $\mathbf{r}$. The scale bars are $10 \mu \mathrm{m}$

MMA) and ADMA, two endogenous inhibitors of nNOS [11] derived from in vivo proteolysis of methylated arginine residues on various proteins. In this respect, a positive correlation has been described between plasma concentrations of ADMA and insulin resistance [28], as well as obesity [29]. Importantly, we observed increased ADMA levels within islets from $f a / f a$ rats and obese individuals. Indeed, methylarginines are transported and concentrated into the cell in competition with arginine by using the cationic amino acid transporters [30]. Our results suggest that ADMA participates in the marked increment in nNOS catalytic inactive dimers we found, which together with our functional data obtained with miconazole and L-NAME, argue that the effect of nNOS on insulin secretion results from a mechanism independent of its classic enzymatic function.

Concerning nNOS subcellular localisation, we observed a greater association of nNOS with insulin secretory granules in beta cells from $f a l f a$ rats and obese humans. Indeed, we have previously shown by electron microscopy that nNOS was present at the level of insulin granules in rat beta cells [10], where the enzyme interacts with its endogenous protein inhibitor, protein inhibitor of neuronal NOS (PIN) [31]. PIN is a highly conserved protein that blocks the enzyme dimerisation and subsequent NO production [32]. However, when nNOS is stabilised in the dimeric conformation by L-NAME, L-MMA or ADMA, PIN is unable to prevent nNOS dimerisation [11], which could explain the high number of dimers we observed in islets from $f a / f a$ rats and obese humans.

It must be emphasised that PIN is also the light chain of cytoplasmic and flagellar dyneins and myosin $\mathrm{V}$, two cytoskeletal components involved in flagellar movements and the traffic of intracellular organelles [33]. In pancreatic beta cell, myosin Va has been involved in the transport of dense-core secretory vesicles [34] and granule recruitment during late-phase secretion [35]. As we have recently characterised a ternary complex between nNOS, PIN and myosin V in INS-1 cells (data not shown), we hypothesise that a greater association of nNOS dimers with PIN and myosin Va could be involved in insulin hypersecretion in $f a / f a$ rats and obese individuals through enhanced intracellular granule trafficking. Such a possibility is strongly supported by the increased association of nNOS with insulin granules we found in $f a / f a$ rats and obese humans that could favour the simultaneous association of the inactive nNOS dimers with PIN/myosin V and insulin granules. This is consistent with the observation that downregulation of nNOS dimers by miconazole brought insulin secretion in $f a / f a$ rats and obese humans back to levels close to those observed in, respectively, $f a /+$ rats and lean individuals.

In addition to insulin secretory granules, nNOS is also located in beta cell mitochondria [10], which are likely to be affected by decreased NO production and to participate in beta cell hyperactivity. We observed modifications in mitochondrial morphology in falfa beta cells, as previously shown in islets from the Zucker diabetic fatty rat [36]. In this respect, NO has been shown to act as a key messenger activating mitochondrial biogenesis in diverse cell types [37] and mitochondrial density has been found lowered in tissues of $n N O S$ knockout animals [38]. NO has also been reported to inhibit mitochondrial respiratory chain complexes I, II and III, and nanomolar concentrations of NO are able to reversibly inhibit cytochrome $c$ oxidase [39]. Therefore, it is tempting to 
Fig. 8 Analysis of nNOS subcellular localisation. a nNOS expression in cytosolic and mitochondrial fractions from $\mathrm{fa} /+$ and $f a / f a$ islets. Subcellular fractionation of islet mitochondria was performed by centrifugation. The presence of nNOS was revealed by western blotting, in parallel with $\alpha$-tubulin, a cytosolic marker, and VDAC, a mitochondrial protein. b-f Subcellular localisation of nNOS in human beta cells by electron microscopy. Insulin and $\mathrm{nNOS}$ (arrow heads) were labelled with, respectively, 5 and $15 \mathrm{~nm}$ gold particles in beta cells from lean (b, mitochondria; $\mathbf{d}$, insulin granules) and obese (c, mitochondria; $\mathbf{e}$ and $\mathbf{f}$, insulin granules) individuals. Original magnification $\times 60,000$
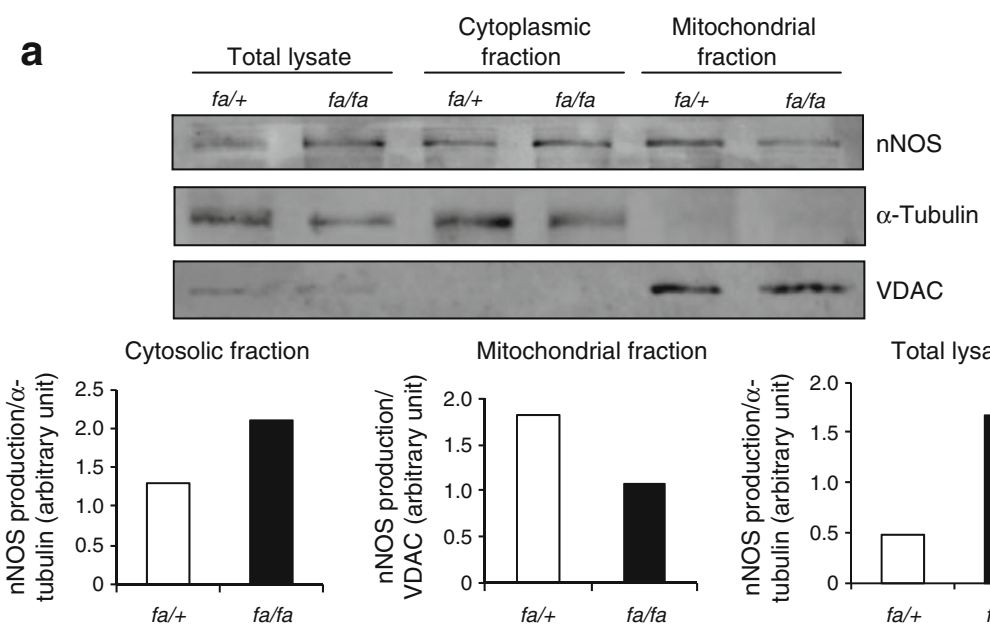

Total lysate
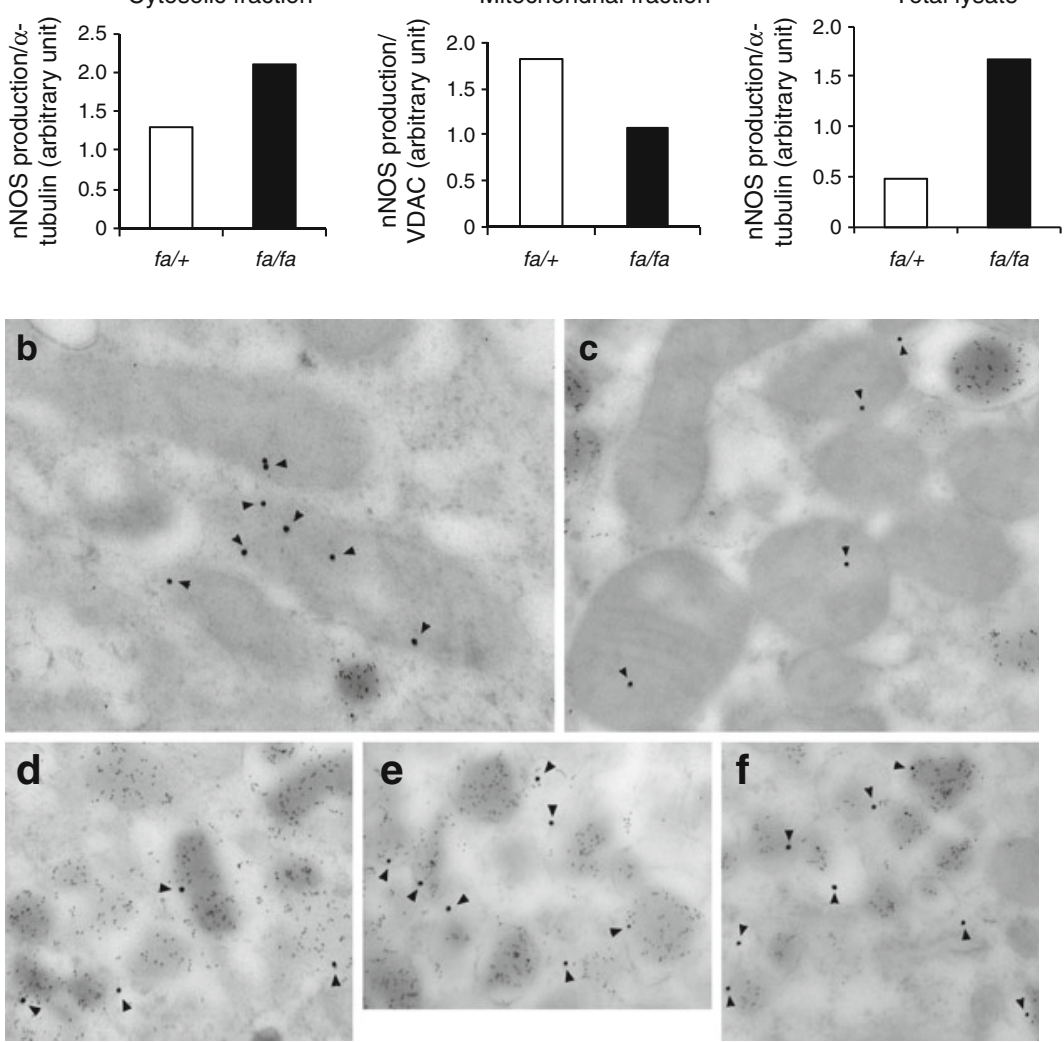

suggest that the decrease in mitochondrial nNOS abundance that appears to occur from our immunofluorescence and subcellular fractionation studies could also be implicated in beta cell hyperactivity.

In conclusion, our data obtained in two models of obesity, the Zucker $f a / f a$ rat and islets from obese humans, provide evidence for a number of nNOS changes likely to participate in hypersecretion of insulin. A major one is the increased formation of resistant nNOS dimers, which could be related to high intracellular amounts of ADMA. In addition, a greater association of nNOS dimers with PIN and myosin Va at the level of insulin secretory granules could significantly increase insulin granule migration and release, and account for, at least partly, insulin hypersecretion in falfa rats and obese humans. Our study could be of pathophysiological relevance as islets from obese organ donors are now used for transplantation in patients with uncontrolled type 1 diabetes [40].
Acknowledgements Human islets were obtained thanks to grant no. 31-2008-416 from the Juvenile Diabetes Research Foundation. A. D. Lajoix was also supported by a grant from the Fondation pour la Recherche Médicale (FRM). We thank M. Manteghetti, S. Dietz, and C. Aknin for their technical contribution.

Contribution statement All authors contributed to the conception, design or analysis and interpretation of data, to drafting and revising the manuscript, and to approval of the final version of the manuscript.

Duality of interest The authors declare that there is no duality of interest associated with this manuscript.

\section{References}

1. Prentki M, Nolan CJ (2006) Islet beta cell failure in type 2 diabetes. J Clin Invest 116:1802-1812

2. Phillips MS, Liu Q, Hammond HA et al (1996) Leptin receptor missense mutation in the fatty Zucker rat. Nat Genet 13:18-19 
3. Pick A, Clark J, Kubstrup C et al (1998) Role of apoptosis in failure of beta-cell mass compensation for insulin resistance and beta-cell defects in the male Zucker diabetic fatty rat. Diabetes 47:358-364

4. Chan CB, MacPhail RM, Mitton K (1993) Evidence for defective glucose sensing by islets of $f a / f a$ obese Zucker rats. Can J Physiol Pharmacol 71:34-39

5. Ferrannini E, Camastra S, Gastaldelli A et al (2004) Beta-cell function in obesity: effects of weight loss. Diabetes 53(Suppl 3): S26-S33

6. Chan CB, Pederson RA, Buchan AM, Tubesing KB, Brown JC (1984) Gastric inhibitory polypeptide (GIP) and insulin release in the obese Zucker rat. Diabetes 33:536-542

7. Liu YQ, Jetton TL, Leahy JL (2002) $\beta$-Cell adaptation to insulin resistance. Increased pyruvate carboxylase and malate-pyruvate shuttle activity in islets of nondiabetic Zucker fatty rats. J Biol Chem 277:39163-39168

8. Nolan CJ, Leahy JL, Delghingaro-Augusto V et al (2006) Beta cell compensation for insulin resistance in Zucker fatty rats: increased lipolysis and fatty acid signalling. Diabetologia 49:2120-2130

9. Moncada S, Palmer RM, Higgs EA (1991) Nitric oxide: physiology, pathophysiology, and pharmacology. Pharmacol Rev 43:109-142

10. Lajoix AD, Reggio $H$, Chardes $T$ et al (2001) A neuronal isoform of nitric oxide synthase expressed in pancreatic beta-cells controls insulin secretion. Diabetes 50:1311-1323

11. Lajoix AD, Pugniere M, Roquet F et al (2004) Changes in the dimeric state of neuronal nitric oxide synthase affect the kinetics of secretagogue-induced insulin response. Diabetes 53:1467-1474

12. Salehi A, Meidute Abaraviciene S, Jimenez-Feltstrom J, Ostenson CG, Efendic S, Lundquist I (2008) Excessive islet NO generation in type 2 diabetic GK rats coincides with abnormal hormone secretion and is counteracted by GLP-1. PLoS One 14:e2165

13. Bucher P, Mathe Z, Morel P et al (2005) Assessment of a novel two-component enzyme preparation for human islet isolation and transplantation. Transplantation 79:91-97

14. Klatt P, Schmidt K, Lehner D, Glatter O, Bachinger HP, Mayer B (1995) Structural analysis of porcine brain nitric oxide synthase reveals a role for tetrahydrobiopterin and L-arginine in the formation of an SDS-resistant dimer. EMBO J 14:3687-3695

15. Hayashi Y, Nishio M, Naito Y et al (1999) Regulation of neuronal nitric-oxide synthase by calmodulin kinases. J Biol Chem 274:20597-20602

16. Sennequier N, Wolan D, Stuehr DJ (1999) Antifungal imidazoles block assembly of inducible NO synthase into an active dimer. J Biol Chem 274:930-938

17. Gross R, Roye M, Manteghetti M, Hillaire-Buys D, Ribes G (1995) Alterations of insulin response to different beta cell secretagogues and pancreatic vascular resistance induced by $N$ omega-nitroL-arginine methyl ester. Br J Pharmacol 116:1965-1972

18. Jetton TL, Lausier J, LaRock K et al (2005) Mechanisms of compensatory beta-cell growth in insulin-resistant rats: roles of Akt kinase. Diabetes 54:2294-2304

19. Chan CB, MacPhail RM, Sheu L, Wheeler MB, Gaisano HY (1999) Beta-cell hypertrophy in falfa rats is associated with basal glucose hypersensitivity and reduced SNARE protein expression. Diabetes 48:997-1005

20. Polonsky KS, Given BD, van Cauter E (1988) Twenty-four-hour profiles and pulsatile patterns of insulin secretion in normal and obese subjects. J Clin Invest 81:442-448

21. Campbell PJ, Gerich JE (1990) Impact of obesity on insulin action in volunteers with normal glucose tolerance: demonstration of a threshold for the adverse effect of obesity. J Clin Endocrinol Metab 70:1114-1118
22. Ferrannini E, Natali A, Bell P, Cavallo-Perin P, Lalic N, Mingrone G (1997) Insulin resistance and hypersecretion in obesity. European Group for the Study of Insulin Resistance (EGIR). J Clin Invest 100:1166-1173

23. Morley JE, Mattammal MB (1996) Nitric oxide synthase levels in obese Zucker rats. Neurosci Lett 209:137-139

24. Carbone DL, Moreno JA, Tjalkens RB (2008) Nuclear factor kappa-B mediates selective induction of neuronal nitric oxide synthase in astrocytes during low-level inflammatory stimulation with MPTP. Brain Res 1217:1-9

25. Liu X, Buffington JA, Tjalkens RB (2005) NF-kappaB-dependent production of nitric oxide by astrocytes mediates apoptosis in differentiated PC12 neurons following exposure to manganese and cytokines. Brain Res Mol Brain Res 141:39-47

26. Karacay B, Li G, Pantazis NJ, Bonthius DJ (2007) Stimulation of the cAMP pathway protects cultured cerebellar granule neurons against alcohol-induced cell death by activating the neuronal nitric oxide synthase (nNOS) gene. Brain Res 1143:34-45

27. Dunbar AY, Kamada Y, Jenkins GJ, Lowe ER, Billecke SS, Osawa Y (2004) Ubiquitination and degradation of neuronal nitric-oxide synthase in vitro: dimer stabilization protects the enzyme from proteolysis. Mol Pharmacol 66:964-969

28. Stuhlinger MC, Abbasi F, Chu JW et al (2002) Relationship between insulin resistance and an endogenous nitric oxide synthase inhibitor. JAMA 287:1420-1426

29. Konukoglu D, Uzun H, Firtina S et al (2007) Plasma adhesion and inflammation markers: asymmetrical dimethyl-L-arginine and secretory phospholipase A2 concentrations before and after laparoscopic gastric banding in morbidly obese patients. Obes Surg 17:672-678

30. Leiper J, Vallance P (1999) Biological significance of endogenous methylarginines that inhibit nitric oxide synthases. Cardiovasc Res 43:542-548

31. Lajoix AD, Badiou S, Peraldi-Roux S et al (2006) Protein inhibitor of neuronal nitric oxide synthase (PIN) is a new regulator of glucose-induced insulin secretion. Diabetes 55:3279-3288

32. Jaffrey SR, Snyder SH (1996) PIN: an associated protein inhibitor of neuronal nitric oxide synthase. Science 274:774-777

33. Benashski SE, Harrison A, Patel-King RS, King SM (1997) Dimerization of the highly conserved light chain shared by dynein and myosin V. J Biol Chem 272:20929-20935

34. Varadi A, Tsuboi T, Rutter GA (2005) Myosin Va transports dense core secretory vesicles in pancreatic MIN6 beta-cells. Mol Biol Cell 16:2670-2680

35. Ivarsson R, Jing X, Waselle L, Regazzi R, Renstrom E (2005) Myosin 5a controls insulin granule recruitment during late-phase secretion. Traffic 6:1027-1035

36. Bindokas VP, Kuznetsov A, Sreenan S, Polonsky KS, Roe MW, Philipson LH (2003) Visualizing superoxide production in normal and diabetic rat islets of Langerhans. J Biol Chem 278:97969801

37. Nisoli E, Clementi E, Paolucci C et al (2003) Mitochondrial biogenesis in mammals: the role of endogenous nitric oxide. Science 299:896-899

38. Schild L, Jaroscakova I, Lendeckel U, Wolf G, Keilhoff G (2006) Neuronal nitric oxide synthase controls enzyme activity pattern of mitochondria and lipid metabolism. FASEB J 20:145-147

39. Brown GC, Cooper CE (1994) Nanomolar concentrations of nitric oxide reversibly inhibit synaptosomal respiration by competing with oxygen at cytochrome oxidase. FEBS Lett 356:295-298

40. Neidlinger NA, Odorico JS, Sollinger HW, Fernandez LA (2008) Can 'extreme' pancreas donors expand the donor pool? Curr Opin Organ Transplant 13:67-71 